\title{
The ITS-90 after definition of neon isotopic reference composition: extent of the isotopic effect tested on previous inter-comparison results
}

\author{
Franco Pavese ${ }^{1, *}$, Anna Szmyrka-Grzebyk ${ }^{1}$, and Peter P.M. Steur ${ }^{2}$ \\ ${ }^{1}$ INTiBS, Wroclaw, Poland \\ ${ }^{2}$ INRIM, Torino, Italy
}

Received: 17 July 2017 / Accepted: 20 October 2017

\begin{abstract}
Starting from the end of the past century, the importance has been recognised of the effect of isotopic composition on some of the temperature fixed points for the most accurate realisations of the ITS-90. In the original definition of the latter, dating back to 1990, only a generic reference was made to "natural" composition of the substances used for the realisation of the fixed points, except for helium. The definition of a reference isotopic composition for three fixed points, $e-\mathrm{H}_{2}, \mathrm{Ne}$ and $\mathrm{H}_{2} \mathrm{O}$, while eliminating the non-uniqueness of the Scale in this respect, induced detectable differences in the present and future realisations of the Scale, at the highest accuracy level, with respect to the previous realisations, when they affected the results of past MRA key comparisons, namely the CCT K1 (and K1.1) and CCT K2 (and K2.1-K2.5) and the related regional and supplementary ones. The paper provides evidence of the extent of this effect by using the results of the relevant key comparisons for neon archived in the BIPM KCDB, and of other comparisons existing in the literature (1979-1984, 2007-2012 and 2009-2010 sealed cell comparisons), and discusses the meaning and the outcomes of this evaluation.
\end{abstract}

Keywords: isotopes / isotopic correction / chemical corrections / neon / triple point / intercomparisons / ITS-90

\section{Introductory notes}

When the current version of the International Temperature Scale, the ITS-90 [1], was promulgated in 1990, the isotopic effect on the Scale was basically ignored, except originally for helium. The Scale definition only made generic reference to a "natural" composition of the substances used for the realisation of the fixed points.

Since the end of the past century, also thanks to the decreased uncertainty of the best realisations of the ITS-90, the effect of the natural variability of the isotopic composition of some of these substances was recognised as an appreciable contribution to the total uncertainty budget of the realisations of those fixed points, in some cases being the largest single contribution [2,3]. In Table 1 this fact is clearly shown. The goal of a total uncertainty budget of $30 \mu \mathrm{K}$ for a measurement on a single cell was reached around 2010 at INRIM [4], PTB and NMIJ.

\footnotetext{
* frpavese@gmail.com

Associated Scientist 2010-2015. Formerly, Consiglio Nazionale delle Ricerche, Italy, until 2006, then INRIM until 2008.
}

\subsection{State of the art}

Isotopic studies were undertaken, initially on $e-\mathrm{H}_{2}$ (HD in $\left.\mathrm{H}_{2}\right)[5,6]$ and $\mathrm{H}_{2} \mathrm{O}\left(\mathrm{D}_{2}\right.$ and $\left.{ }^{18} \mathrm{O}_{2}\right)$ [7-10], and later also on $\mathrm{Ne}$ $[4,11-15]$.

They are relevant to ITS-90, since the triple points of $e$ $\mathrm{H}_{2}$ and $\mathrm{Ne}$ are required in SPRT subrange 2 (25-273.16) K. The vapour pressure points at $\approx 17$ and $\approx 20.3 \mathrm{~K}$ of $e-\mathrm{H}_{2}$ are required in the range (13.8-273.16) K. The use of the triple point of water (TPW), which can presently be realised also in small metallic sealed cells $[16,17]$, is prescribed for the whole part of the ITS-90 that is based on resistancethermometer ratios, extending below $273.16 \mathrm{~K}$ down to $13.8 \mathrm{~K}$ and above $273.16 \mathrm{~K}$ up to the silver point, so affecting also all comparisons including these ranges, based on the resistance ratios $W=R\left(T_{90}\right) / R(\mathrm{TPW})$.

In addition, the triple points of $e-\mathrm{H}_{2}$ and Ne also affect the range covered by the interpolating gas thermometer (ICVGT), being two of the three fixed points of the ICVGT defined by the ITS- 90 in the range $3-25 \mathrm{~K}-$ the third being the boiling point of ${ }^{4} \mathrm{He}$ ( or $\left.{ }^{3} \mathrm{He}\right)$.

At the time when the key comparisons (KC) CCT-K1 "Realisations of the ITS-90, $0.65 \mathrm{~K}$ to $24.5561 \mathrm{~K}$, using rhodium-iron resistance thermometers" (1997-2001) [18], CCT-K2 "Key "Comparison of capsule-type standard 
Table 1. Typical and aimed uncertainty budget for cryogenic fixed point measurements [3].

\begin{tabular}{lllll}
\hline$\#$ & Item & Typical $1975-2000(\mu \mathrm{K})$ & Available in $2006(\mu \mathrm{K})$ & Aimed in future $(\mu \mathrm{K})$ \\
\hline 1 & Non-isotopic impurities & $50 \Rightarrow 2000^{4}$ & 40 & 10 \\
2 & Isotopic composition $^{*}$ & $\mathrm{Up} \mathrm{to} 700^{5}$ & $30^{6}$ & 20 \\
3 & ${\text { Induced by } R_{\mathrm{cs}}}$ & $50-200$ & 30 & 10 \\
4 & Induced by $\tau_{5}$ & $<100$ & 20 & 10 \\
6 & Cryostat other effects $^{1}$ & $20-300$ & 10 & 10 \\
7 & Resistance measurement $^{2}$ & $30-200$ & 30 & 0 \\
& $T_{\text {tp definition }}{ }^{3}$ & $20-300$ & 20 & 30 \\
\end{tabular}

Legend: $R_{\mathrm{cs}}=$ static thermal resistance; $\tau=$ cell dynamic time constant; $T_{\mathrm{tp}}=$ triple point temperature.

${ }^{1}$ For meltings lasting less than $\approx 12 \mathrm{~h}$. ${ }^{2}$ Except with $e-\mathrm{H}_{2}$ when measuring a CSPRT. ${ }^{3}$ For $\Delta T_{\text {melt }(20-80 \%)}<\approx 0.1 \mathrm{mK}$. ${ }^{4}$ For Ar in $\mathrm{O}_{2}$ or $\mathrm{HD}$ in $\mathrm{D}_{2} \cdot{ }^{5}$ For D in H. ${ }^{6}$ For the best assay uncertainty only. ${ }^{7}$ Equivalent to $\approx 1 \mu \Omega$ for a SPRT above $40 \mathrm{~K}$.

platinum resistance thermometers from $13.8 \mathrm{~K}$ to $273.16 \mathrm{~K}$ " (1997-1999) [19] and CCT-K7 "Key comparison of water triple point cells" (2002-04) [20], were organised and completed, the above issue was not yet recognised as important, so not yet formally included in the protocols. Subsequent CCT-K1.1 (2006-14, results available in the BIPM KCDB only recently) [21] and EUROMET.T-K1 (2008-12, similarly) [22] did not take the isotopic effect into account, except for INRIM. CCT-K2.1 (2003) [23] and CCT-K2.4 (2006) [24] did not take the isotopic effect into account; CCT-K2.3 (2006) [25] did take the isotopic effects into account (official correction for $e-\mathrm{H}_{2}$ and $\mathrm{H}_{2} \mathrm{O}$; VSL unofficial evaluation for $\mathrm{Ne}$, see the separate file of the Online Supplementary Information (OSI)); also CCT-K2.5 (2015) [26] did take the isotopic effects into account; CCT-K2.2 (2014) [27], not yet completed, will also take the isotopic effects into account. The EUROMET.T-K7.1 (2008-2009) [28] and APMP.T-K7 [29] included (optionally in the former) the isotopic issue in the comparisons for water.

For water, the issue also involves the present definition of the kelvin, modified in 2005 to include a reference isotopic composition [30]. In the ITS-90, for $e-\mathrm{H}_{2}$ and $\mathrm{H}_{2} \mathrm{O}$, corrections to a reference composition were made formally available since the first version of the Technical Annex to the Mise en pratique of the kelvin in 2006; for neon it was since its 2014 version [31].

At present, several cases are known of ITS-90 national realisations having adopted, at least partially, isotopic reference compositions: for example, NIST for the all ranges between 4 and $273.16 \mathrm{~K}$ only for $e-\mathrm{H}_{2}$ and of $\mathrm{H}_{2} \mathrm{O}$ [32]; INRIM for both $e-\mathrm{H}_{2}$ and Ne affecting the ICVGT [33].

\subsection{Aim of this paper}

The study in this paper intends to provide evidence of the consequences of taking the isotopic effect into account. This is best done by using the outcomes of inter-comparisons, because one can also understand to which extent such a correction have affected, and will possibly affect, the differences between laboratories, when they were obtained in studies not having taken that effect into account. In particular, the scrutiny of key comparisons already available from the BIPM KCDB is important, because that MRA exercise provides to metrology the most valuable results, also in respect to the $\mathrm{CMC}$ declarations. However, this paper does not intend to tackle any formal consequence that may arise from, or be related to, the isotopic corrections.

In general, a study on the effect that the correction for the isotopic composition may have on the realisation of the ITS-90 in each laboratory is worthwhile if three conditions are met:

- the isotopic composition of the samples used in a comparison are known;

- the equation to compute the temperature correction is included in the current Annex to the MeP of the kelvin; - the correction can be applied to the results of a substantial number of participants to the comparison.

In addition, no significant effect due to possible remaining chemical impurities should exists, or it has to be taken in account (see for neon the OSI).

Hydrogen.The present information concerning the isotopic correction for hydrogen in CCT-K1 and K1.1 comparisons is quite limited, so the third condition is not met. In addition, the effect of the correction on the latter is almost irrelevant with respect to the comparison uncertainty. Similarly, for the CCT-K2. $x$ the third condition is not met.

Water. The effect of water isotopic composition will not be analysed in this paper, being minimal in the temperature range below $25 \mathrm{~K}$.

Neon. For neon it is possible to assign the isotopic composition to the gas samples used in a few open-cell realisations or contained, in most cases, in permanentlysealed cryogenic metal cells [13]. In these cases, it is possible to apply the equations in the ITS-90 Technical Annex [31] and compute the results at the reference composition. For neon all the above conditions are met for the CCT-K2, K2.1, $\mathrm{K} 2.3-\mathrm{K} 2.5$ (for the chemical impurity corrections see later Tab. 3 and the OSI).

In addition, some data are also traceable to the first International Inter-comparison of sealed cells performed in 1978-84 [34] or also ensures traceability for several results of the 1997-2005 Star Inter-comparison [12]. 


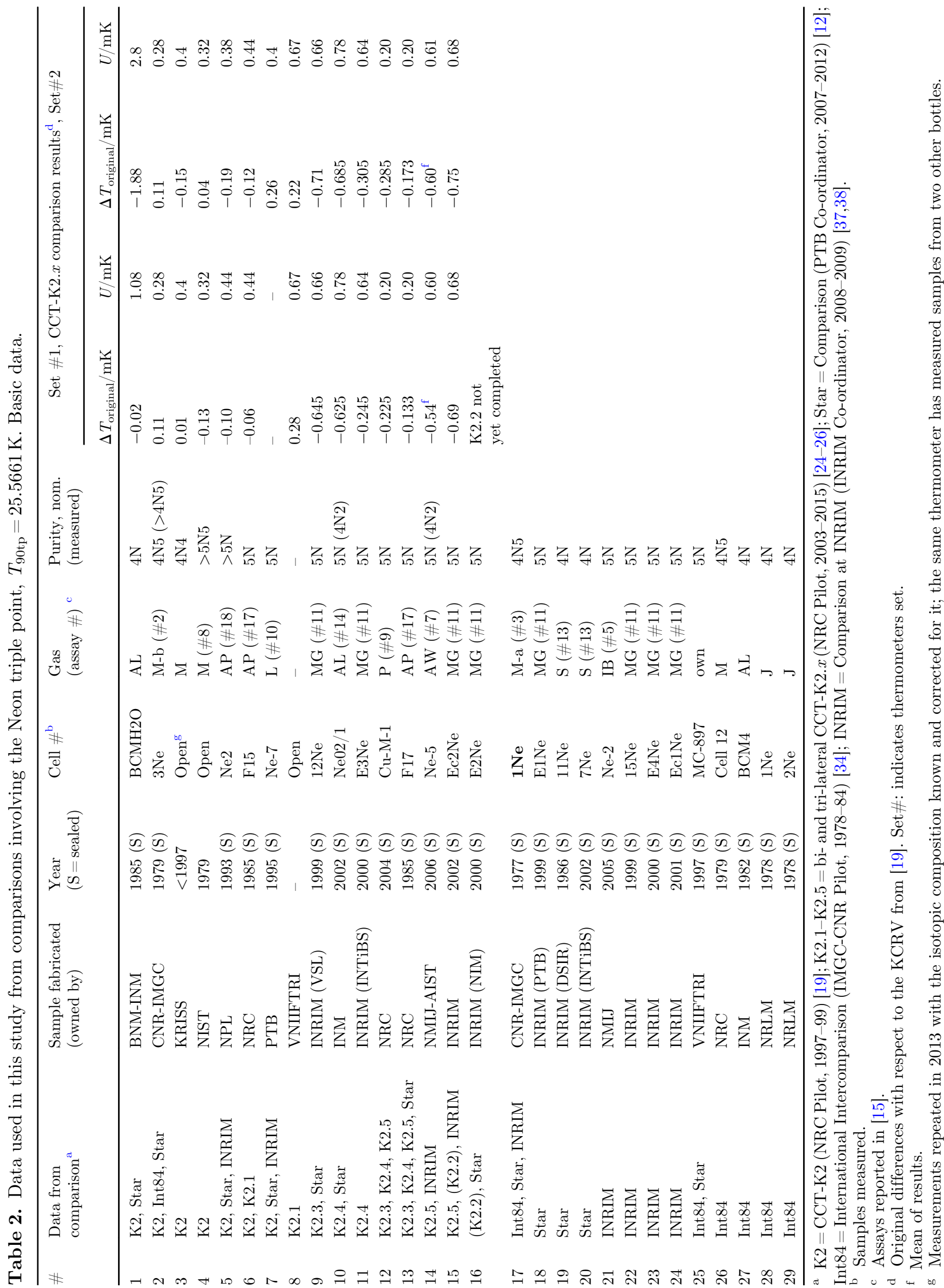




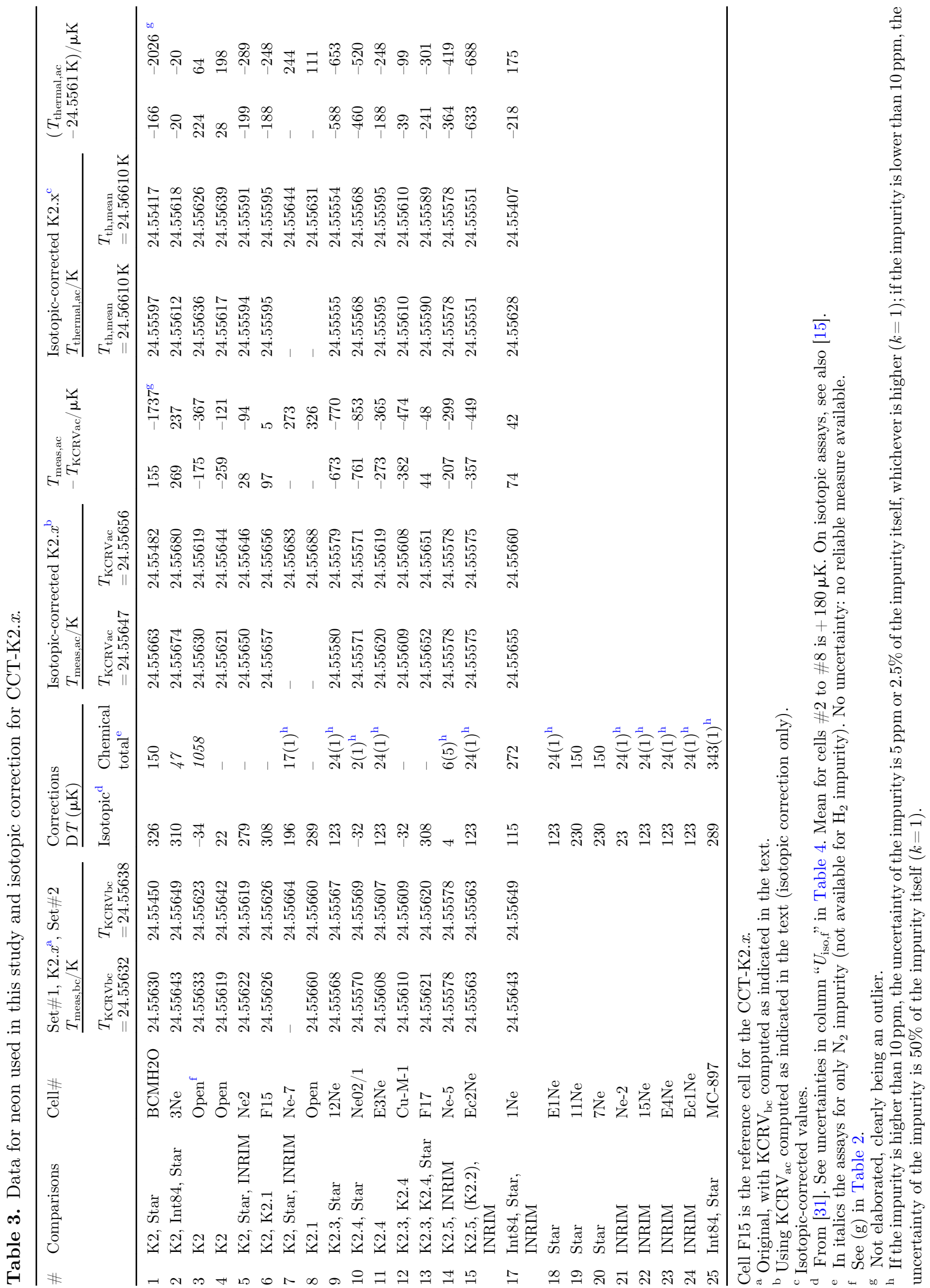


Therefore, in this paper the computation of the corrections and the discussion of some consequences is limited to neon, as an example of the complexity of the information needed to perform sound corrections, which may also affect the same type of corrections for other substances. See [35] for the way the information drawn from [31] should be used to take isotopic composition into account in the calibration of SPRTs on the ITS-90, and [15] for details about the needed isotopic-composition assays and their outcomes.

In the OSI, the effects of the chemical impurities in neon are briefly presented, presently not subject to correction according to [31] but only considered as an uncertainty component, to compare the importance of their effect with the isotopic effect.

\section{Isotopic effects on ITS-90 for the neon triple point temperature $(24.5561 \mathrm{~K})$}

During a worldwide study lasted about 10 years, 26 different bottles of high-purity neon of commercial origin obtained from distillation of air, plus three certified reference mixtures, were studied, including isotopic composition and chemical impurities assays; thermal studies were performed on 34 samples drawn from them [13]. These studies and the subsequent ones on pure ${ }^{20} \mathrm{Ne}$ and ${ }^{22} \mathrm{Ne}$ samples [13] led to the equation, now included in [31], relating $T_{90 \text {,ref }}$ (ITS-90 defined value) to the value $T_{90}$ for the isotopic composition of the sample used, and allow to compute, from the measured resistance-ratio value, the corresponding value at $T_{90, \text { ref }}[35]$.

In Table 2 the data are reported for the outcomes of several comparisons concerning neon, and in Table 3 the results for the CCT-K2. $x$ of having taken into account the isotopic effect, based on the assay values selected after the critical evaluation of the assays, and their associated uncertainties $[13,15] .{ }^{1}$ In Table 5 the results of the isotopic corrections for the Star Inter-comparison are reported [12]. For important specific conditions concerning the way the data of each laboratory were obtained, see the OSI associated with this paper.

\subsection{Taking the effect of the isotopic composition into account}

We recall here that, according to the MRA, the key comparison reference value (KCRV) of the comparison CCT-K2 is common to all the subsequent integrations of its results with the results of the subsequent supplementary comparisons. It is not affected by uncertainty, as indicated in [19].

In order to take the effect of the isotopic composition on $T_{\mathrm{tp}, \mathrm{Ne}}$ into account, it is useful to summarise the exact meaning of the CCT-K2 results (not including the CCTK2.x), and the procedure for applying the isotopic correction to them

\footnotetext{
${ }^{1}$ All uncertainties $u$ in this paper are the standard deviations $(k=1) ; U$ is the expanded uncertainty $(k \approx 2)$.
}

(a) Each participant used a sample of neon whose effect of the isotopic composition, at that time, was taken into account in the uncertainty budget only. This contribution to uncertainty is reported in Table 4, whose mean value amounts to $305 \mu \mathrm{K}$ out of $361 \mu \mathrm{K}$ of the total mean laboratory budget $(85 \%)$ and out of $517 \mu \mathrm{K}$ of the total comparison mean budget (59\%) - so being the dominant contribution.

(b) The results of the realisation of the triple point temperatures were compared through exchange of thermometers calibrated without taking into account the isotopic effect. However, being the triple point of neon a fixed point of the ITS-90, each participant laboratory associated to the provided measured value of the resistance ratio $R_{\mathrm{tp}, \mathrm{Ne}} / R_{\mathrm{TPW}}$ the ITS-90 temperature value, $24.5661 \mathrm{~K}$, exact. When the thermometers were compared in a comparison block at NRC, the measured resistance ratios did not exactly reproduce the supplied values - being that evidence the very reason of the comparison.

(c) According to the CCT-K2 protocol, although one cell (NRC F15) was taken as the reference, the value $24.5561 \mathrm{~K}$ was not associated to it as the KCRV of the comparison. Instead, the resulting differences in the results, expressed as $\Delta T_{\text {meas, }}$, were computed in [19] with respect to a $T_{\mathrm{KCRV}}$ being the weighted mean of the resulting temperatures. ${ }^{2}$

(d) Normally those differences would directly express the difference in the realisations of the fixed point between the participant laboratories, $T_{\text {thermal }}$, due to thermal or technical effects. However, in this case, the measured temperatures were instead $T_{\text {meas }}=T_{\text {thermal }}+\mathrm{D} T$, where: - a $\mathrm{D} T_{x}$ is the temperature difference due to the isotopic composition of a sample with respect to the reference composition defined after 2014 , the ${ }^{\text {IUPAC }_{x}}$ $(\mathrm{Ne})$ one. Thus the corrections $\mathrm{D} T_{x}=T_{\text {meas, }}$

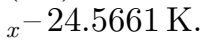

- all the remaining items of the uncertainty budget that are usual in a comparison, are taken into account for $T_{\text {thermal }}$. Notice that the $\mathrm{KCRV}_{\mathrm{bc}}$ used in [19] is affected by the D $T_{x}-$ see item (f) below. ${ }^{3}$ Thus, $\quad T_{\text {thermal }}=T_{\text {meas }}-\mathrm{D} T_{x}=T_{\text {meas }}-\left(T_{x}-24.5661\right.$ $\mathrm{K})=24.5661 \mathrm{~K}+\left(T_{\text {meas }}-T_{x}\right)$. However, the final aim of this paper is instead to find $\delta T_{\text {thermal }}=$ $T_{\text {thermal }}-\mathrm{KCRV}_{\mathrm{ac}}$.

(e) Let us start from the fact that $\Delta T=T_{\text {meas }}-T$ $\left(\mathrm{KCRV}_{\mathrm{bc}}\right)=T_{\text {meas }}-\operatorname{wmean}\left(T_{\text {meas }}\right)$. This can be approximated by replacing the weighted mean with the simple mean: $\Delta T=T_{\text {meas }}$ $\operatorname{mean}\left(T_{\text {meas }}\right)=T_{\text {meas }}-\operatorname{mean}\left(T_{\text {thermal }}\right)-\operatorname{mean}(\mathrm{D} T)=$ $T_{\text {thermal }}+\mathrm{D} T-$ mean $\left(T_{\text {thermal }}\right)-$ mean $(\mathrm{DT})$.

\footnotetext{
${ }^{2}$ In this paper, the Greek $\Delta$ is used for differences before isotopic correction (e.g., $\Delta T_{\text {meas }}=\Delta_{\text {or }}$ in Table 2), while capital Roman D is used for the isotopic effect - see text in (d). In this paper the differences due to a different amount of chemical impurities is not considered - see the OSI.

${ }^{3}$ In this paper subscripts bc - for before correction - and ac - for after correction - are used. Thus the KCRVs are indicated in the following as $\mathrm{KCRV}_{\mathrm{bc}}$ and $\mathrm{KCRV}_{\mathrm{ac}}$, respectively.
} 


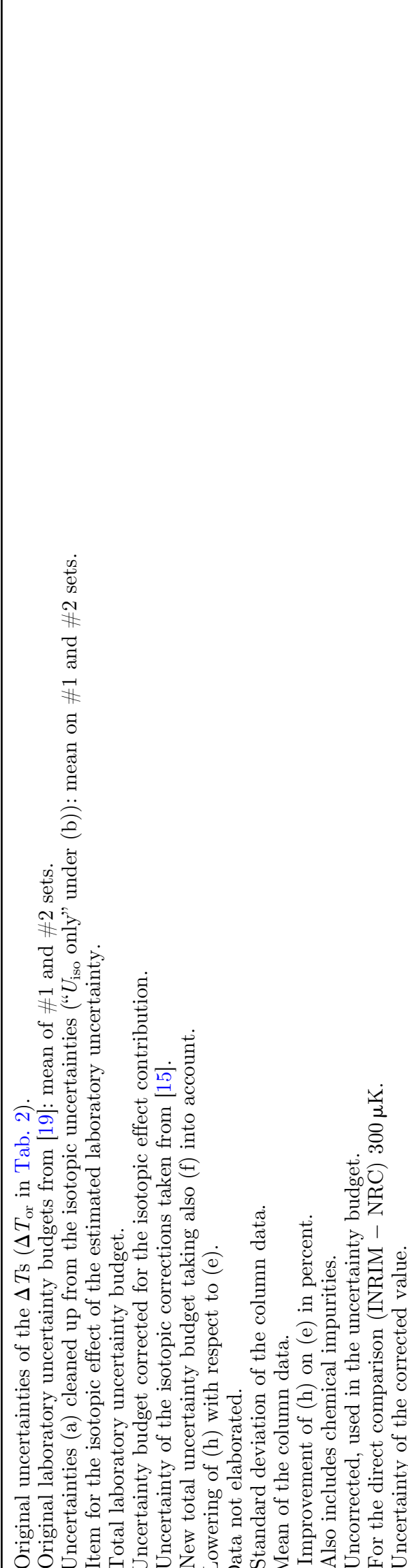

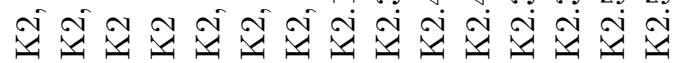


Table 5. Data for neon used in this study: isotopic correction for the Star Cell Intercomparison [6].

\begin{tabular}{|c|c|c|c|c|c|c|c|}
\hline \multirow[t]{2}{*}{ Comparisons } & \multirow[t]{2}{*}{$\#$} & \multirow{2}{*}{$\begin{array}{l}\text { Cell, fabricated } \\
\text { (measured) }\end{array}$} & \multirow{2}{*}{$\begin{array}{l}\text { Sealing } \\
\text { date }\end{array}$} & \multirow[t]{2}{*}{ Cell } & \multirow{2}{*}{$\begin{array}{l}\text { Gas } \\
\text { (\#analysis) }\end{array}$} & \multicolumn{2}{|c|}{ Star (Ref: PTB Ne-7) } \\
\hline & & & & & & $\mathrm{D} T=$ cell-ref & $\mathrm{D} T$ corrected \\
\hline K2, Star & 1 & BNM-INM & 1985 & ВСМH2O & AL1 (\#19) & 210 & 80 \\
\hline Int84, Star & 3 & CNR-IMGC & 1979 & $3 \mathrm{Ne}$ & M-b $(\# 2)$ & 66 & -49 \\
\hline K2 & 4 & (KRISS) & Open & Open & M & & \\
\hline K2 & 5 & (NIST) & Open & Open & $\mathrm{M}(\# 8)$ & & \\
\hline K2, Star, INRIM & 6 & NPL & 1993 & $\mathrm{Ne} 2$ & $\mathrm{AP}(\# 18)$ & 132 & 49 \\
\hline $\mathrm{K} 2, \mathrm{~K} 2.1$ & 7 & NRC & 1985 & F15 & $\mathrm{AP}(\# 17)$ & & \\
\hline K2, Star, INRIM & 8 & РTB & 1995 & $\mathrm{Ne}-7^{\mathrm{a}}$ & $\mathrm{L}(\# 10)$ & $0^{\mathrm{a}}$ & 0 \\
\hline K2.3, Star & 10 & INRIM (VSL) & 1999 & $12 \mathrm{Ne}$ & MG $(\# 11)$ & -62 & 9 \\
\hline K2.4, Star & 11 & INM & 2002 & $\mathrm{Ne} 02 / 1$ & AL2 $(\# 14)$ & 8 & 236 \\
\hline $\mathrm{K} 2.4$ & 12 & INRIM (INTiBS) & 2000 & $\mathrm{E} 3 \mathrm{Ne}$ & MG $(\# 11)$ & & \\
\hline $\mathrm{K} 2.3, \mathrm{~K} 2.4$ & 13 & NRC & 2004 & $\mathrm{Cu}-\mathrm{M}-1$ & $\mathrm{P}(\# 9)$ & & \\
\hline K2.3, K2.4, Star & 14 & $\mathrm{NRC}$ & 1985 & F17 & $\mathrm{AP}(\# 17)$ & 170 & 58 \\
\hline$(\mathrm{K} 2.2)$ & 15 & INRIM (NIM) & 2000 & $\mathrm{E} 2 \mathrm{Ne}$ & MG $(\# 11)$ & & \\
\hline K2.5, INRIM & 16 & NMIJ & 2006 & Ne-5 & $\mathrm{AW}(\# 7)$ & & \\
\hline INRIM & 17 & NMIJ & 2005 & Ne-2 & $\mathrm{IB}(\# 5)$ & & \\
\hline K2.5, (K2.2), INRIM & 18 & INRIM & 2002 & $\mathrm{Ec} 2 \mathrm{Ne}$ & MG (\#11) & & \\
\hline Int84, Star, INRIM & 2 & CNR-IMGC & 1977 & $1 \mathrm{Ne}$ & $\mathrm{M}-\mathrm{a}(\# 3)$ & 37 & 117 \\
\hline Star & 19 & INRIM (PTB) & 1999 & E1Ne & MG (\#11) & -23 & 48 \\
\hline Star & 20 & INRIM & 1986 & $11 \mathrm{Ne}$ & $\mathrm{S}(\# 13)$ & 55 & 21 \\
\hline INRIM & 21 & INRIM & 1999 & $15 \mathrm{Ne}$ & MG (\#11) & & \\
\hline INRIM & 22 & INRIM & 2000 & $\mathrm{E} 4 \mathrm{Ne}$ & MG (\#11) & & \\
\hline INRIM & 23 & INRIM & 2001 & $\mathrm{Ec} 1 \mathrm{Ne}$ & MG (\#11) & & \\
\hline Star & 24 & INRIM (INTiBS) & 2002 & $7 \mathrm{Ne}$ & $\mathrm{S}(\# 13)$ & 77 & 43 \\
\hline Int84, Star & 25 & VNIIFTRI & 1997 & MC-897 & Own & 156 & 63 \\
\hline Int84 & 26 & $\mathrm{NRC}$ & 1979 & Cell 12 & M & & \\
\hline Int84 & 27 & INM & 1982 & BCM4 & $\mathrm{AL}$ & & \\
\hline Int84 & 28 & NRLM & 1978 & $1 \mathrm{Ne}$ & $\mathrm{J}$ & & \\
\hline Int84 & 29 & NRLM & 1978 & $2 \mathrm{Ne}$ & $\mathrm{J}$ & & \\
\hline Star & 30 & INM & 1999 & $\mathrm{Ne} 99 / 2$ & AL2 (\#19) & 205 & 75 \\
\hline Star & 31 & PTB & 1995 & $\mathrm{Ne}-12$ & $\mathrm{~L}(\# 10)$ & 8 & 8 \\
\hline Star $^{b}$ & 32 & NIST & 1998 & NIST201 & Math $(\# 20)^{\mathrm{b}}$ & 130 & $302^{\mathrm{b}}$ \\
\hline
\end{tabular}

a Reference cell.

b Uncertain filling-gas attribution to a bottle. Not elaborated.

(f) Then, one can compute the net contribution for each sample:

$$
\begin{aligned}
T_{\text {thermal }, x} & =\operatorname{mean}_{\mathrm{ac}}\left(T_{\text {thermal }}\right)+\Delta T_{\text {meas }, \mathrm{x}} \\
& -\mathrm{D} T_{\mathrm{x}}+\operatorname{mean}\left(\mathrm{D} T_{x}\right) .
\end{aligned}
$$

where the last term takes into account the offset in the original $\mathrm{KCRV}_{\mathrm{ac}}$, and finally, $\delta T_{\text {thermal }}=\left[\operatorname{mean}_{\mathrm{ac}}\left(T_{\text {thermal }}\right)+\right.$ $\left.\Delta T_{\text {meas }, x^{-}}\left(\mathrm{D} T_{x}-\operatorname{mean}\left(\mathrm{D} T_{x}\right)\right)\right]-\operatorname{mean}\left(T_{\text {thermal }}\right)$ :

$$
\delta T_{\text {thermal }}=\Delta T_{\text {meas }, x}+\left(\operatorname{mean}\left(\mathrm{D} T_{x}\right)-\mathrm{D} T_{x}\right) .
$$

The method used in this paper aims at implementing the above procedure based on temperature values. First, one needs to compute the value of $\mathrm{KCRV}_{\mathrm{bc}}$, not explicitly reported in [19].

\subsubsection{Main comparison (CCT-K2)}

The comparison did not define a "reference cell" to which assign the ITS-90 value, $24.5561 \mathrm{~K}$ but, as recalled above, the temperature value of the KCRV of CCT-K2 was computed as the weighted mean of the temperature values measured in the comparison block by each calibrated thermometer participating in the comparison, leading to the $\Delta T_{\text {original }}$ values in Table 2: the value of $T_{90, \mathrm{~K} 2}$ assigned to the KCRV was not indicated in the Final Report. 


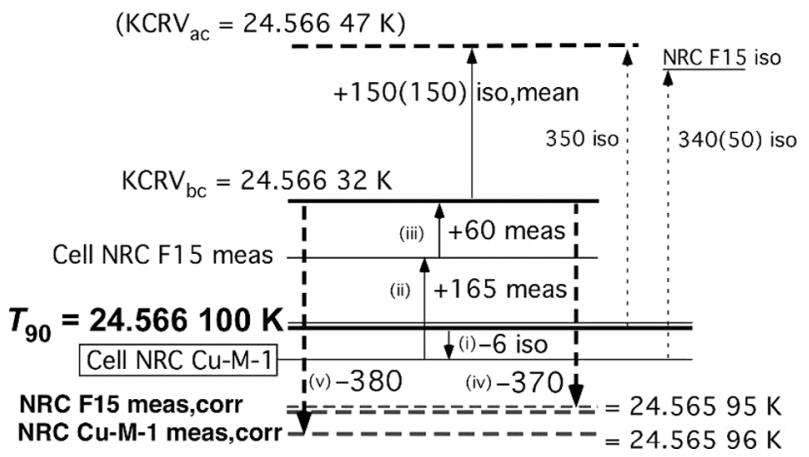

Fig. 1. Graphical representation of the procedure described in Section 2.1.1 for set \#1.The procedure starts from cell NRC CuM-1, step (i), where $T_{\text {ref }}=T_{90, \mathrm{Ne}}=24.5561 \mathrm{~K}$. For the $\mathrm{KCRV}_{\mathrm{ac}}$ see Table 3 and Figure 2 The $\mathrm{KCRV}_{\mathrm{ac}}$ is $24.56647 \mathrm{~K}$.

When instead the isotopic composition is taken into account, an arbitrary choice for $T_{\mathrm{KCRV}}$ is not allowed anymore, since the ITS-90 definition was later integrated by attributing the value $24.5561 \mathrm{~K}$ to, and only to, neon having the reference isotopic composition, the one recommended by IUPAC, ${ }^{\text {IUPAC }} x(\mathrm{Ne}):{ }^{22} x=0.0925$; ${ }^{21} x=0.0027 ;{ }^{20} x=$ the rest [36].

This means that, in principle, the CCT-K2 KCRV after correction is unlikely to be equal to the CCT-K2 KCRV before correction, i.e. to the one used to express the differences in Table 2.

The $T_{90}\left(\mathrm{KCRV}_{\mathrm{ac}}\right)$ and difference $\left(\mathrm{KCRV}_{\mathrm{ac}}-\mathrm{KCRV}_{\mathrm{bc}}\right)$ can now be evaluated with good approximation. Should the KCRV be the simple mean of the $T_{\text {meas }}$, it would be exact to say that $\mathrm{KCRV}_{\mathrm{ac}}=\mathrm{KCRV}_{\mathrm{bc}}+\operatorname{mean}\left(\mathrm{D} T_{x}\right)$; in this case it is a good approximation because the corrections are small with respect to the temperature values. In addition, as illustrated in Section 2.1, one is not interested in the $\mathrm{KCRV}_{\mathrm{ac}}\left(T_{\text {meas }}\right)$, as it would directly come from the elaboration of the Final Report of CCT-K2, but in the $\operatorname{KCRV}_{\text {ac }}\left(T_{\text {thermal }}\right)$, i.e. based on the measured values cleaned from the isotopic effect, $T_{\text {thermal }}=T_{\text {meas }}-\mathrm{D} T_{x}$.

Being not all corrections necessarily exactly consistent with each other, the resulting value of the $\mathrm{KCRV}_{\mathrm{ac}}$ can vary somewhat depending on the correction chosen as the reference (exact) one.

In order to first obtain the value of the $\operatorname{KCRV}_{\mathrm{bc}}\left(T_{\text {meas }}\right)$, the method used in this paper is the following (where \#1 and \#2 indicate the thermometer set) ${ }^{4}$ :

(i) the value $T_{90}(\mathrm{Ne})=24.5561 \mathrm{~K}$, exact, corresponds to ${ }^{\mathrm{IUPAC}} x(\mathrm{Ne})$

(ii) a reference sample is chosen. The choice of the NRC F15 sample seems the most obvious, since NRC was the pilot in all K2.x comparisons;

(iii) for NRC's last reference cell, $\mathrm{Cu}-\mathrm{M}-1$, the isotopiceffect difference to ${ }^{\text {IUPAC }} x(\mathrm{Ne})$ is $\mathrm{D}_{\mathrm{Cu}-\mathrm{M}-1}=-6$ (94) $\mu \mathrm{K}$;

(iv) thus, the ITS-90 value of the NRC Cu-M-1 cell is $T_{90}(\mathrm{Cu}-\mathrm{M}-1)_{\mathrm{ac}}=24.56609_{4} \mathrm{~K}$;

\footnotetext{
$\overline{{ }^{4} \text { These values, as all the }} \Delta T_{\text {meas }}$, are affected by the lack of isotopic correction.
}

(v) the NRC difference measured through cell F17 [T $(\mathrm{Cu}-\mathrm{M}-1)-T(\mathrm{~F} 15)]_{\mathrm{bc}}=-165(200) \mu \mathrm{K}$, so one gets

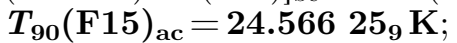

(vi) the differences $\Delta T_{\mathrm{F} 15}$ indicated in [19, exCCT-K2] are $\Delta T_{\mathrm{F} 15 \# 1}=T(\mathrm{~F} 15-\mathrm{KCRV})_{\# 1}=-0.06(44) \mathrm{mK}$ and $\Delta T_{\mathrm{F} 15 \# 2}=T(\mathrm{~F} 15-\mathrm{KCRV})_{\# 2}=-0.12(44) \mathrm{mK}$;

(vii) thus $\boldsymbol{T}_{\mathbf{9 0}}\left(\mathrm{KCRV}_{\mathrm{bc}}\right)_{\# \mathbf{1}} \approx \mathbf{2 4 . 5 6 6} \quad \mathbf{3 2} \mathrm{K}$ and $T_{90}\left(\mathrm{KCRV}_{\mathrm{bc}}\right)_{\# 2} \approx \mathbf{2 4 . 5 6 6} 38 \mathrm{~K}$;

(viii) incidentally, the isotopic-effect from the assays is [T $(\mathrm{Cu}-\mathrm{M}-1)-T(\mathrm{~F} 15)]=-342(95) \mu \mathrm{K}$ : this is not a discrepancy since it is a different component of the cell differences.

Figure 1 depicts graphically the above procedure.

The temperatures actually measured during the CCT$\mathrm{K} 2, T_{\text {meas }}$, are obtained by adding to $T_{\mathrm{KCRVbc}}$ the $\Delta T_{\text {meas }}$ values recorded under "results" in [19] for each sample.

One could then compute the $T_{\text {meas,ac }}$ by simply adding to $\Delta T_{\text {meas }}$ the D $T_{x}$ obtained from the ITS-90 Technical Annex of [31], and then compute the weighted mean from the latter set, for both sets $\# 1$ and $\# 2: \delta T_{\text {meas,ac }}=$ $T_{\text {meas,corr }}-T\left(\mathrm{KCRV}_{\mathrm{ac}}\right)$. The isotopic corrections are reported in Table 3 in the column "Isotopic D T', For the isotopic composition of the samples, see [13-15]. The $\mathrm{KCRV}_{\mathrm{ac}}$ are reported in Table 3: $T_{\mathrm{KCRVac}}=24.56647_{1} \mathrm{~K}$ for thermometers $\# 1$, and $T_{\mathrm{KCRVac}}=24.56655_{8} \mathrm{~K}$ for thermometers $\# 2$, different, as expected, from the KCRVs before correction: notice that these values correspond to the values in item (viii) above well within the uncertainties. That change alone entails changes of $+0.15 \mathrm{mK}$ and $+0.18 \mathrm{mK}$, respectively, to all the $\Delta T_{\text {meas }}=T_{90 \mathrm{bc}}-$ $T_{\text {KCRVbc }}$ in Table 3 - and in Sections 2.1.4-2.1.6 - but note that pair differences are unaffected. ${ }^{5}$

However, the above computation is of limited interest, since the $T_{\text {meas }}$ are those biased by the isotopic effect through $\Delta T$. They should be transformed into the $T_{\text {thermal }}$, according to the procedure indicated in Section 2.1, approximated by using the simple mean of the $T_{\text {meas }}$.

Starting from equation (1) in Section 2.1(f), the values known in it are those for: all $\Delta T_{x}$ from [19] and all $\mathrm{D} T_{x}$ from [31]. Note that equation (1), does not contain any absolute value of $T$, but only mean or relative values: however, one obtains the temperature values in Table 3 as $T_{\text {thermal }}=$ $24.566100 \mathrm{~K}+\delta T_{90, \text { thermal }}$. The $\delta T_{90 \text {,thermal }}$ after correction replace the $\Delta T_{\text {meas }}$ before correction.

The summary of the uncertainties is reported separately in Table 4 - and commented in Section 2.2.

It is interesting to compare the $\delta T_{90 \text {,thermal with the }}$ $\delta T_{\text {meas,ac }}$ computed before. Both are approximated: the latter because, as said, they use $T_{\text {meas }}$; the former because the simple mean replaced the weighted mean and they still use the $\Delta T$. However, the difference between the two is fixed and only $+40 \mu \mathrm{K}$ for $\# 1$ and $+95 \mu \mathrm{K}$ for $\# 2$. The reason is that $\delta T_{90 \text {, thermal }}-\delta T_{\text {meas, ac }}=\mathrm{KCRV}_{\mathrm{bc}}-$ $24.5661 \mathrm{~K}-\operatorname{mean}\left(\mathrm{D} T_{x}\right)$.

\footnotetext{
${ }^{5}$ The new KCRVs were obtained by omitting the INM datum, probably already omitted from the KCRV computation by NRC in the Final Report, and by including KRISS, whose datum was not processed in the Final Report [19].
} 


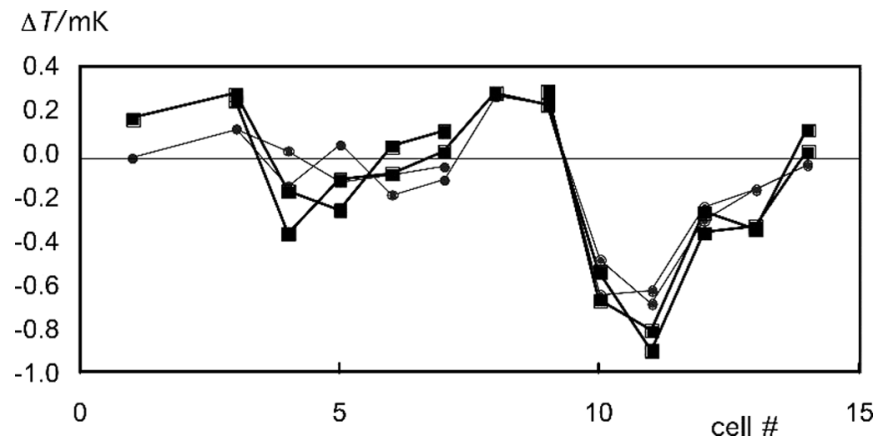

Fig. 2. Graphical representation of the corrected data $\Delta T=$ $\left(T_{\text {meas ac }}-T_{\text {KCRVac }}\right)$ from Table 3 and the uncorrected data $\Delta T=\Delta T_{\text {original }}$ from Table 2 , for cells $\# 1$ to $\# 15$ and for thermometer sets \#1 and \#2. Gray dots and lines: uncorrected differences. Black squares and lines: isotopic-corrected differences.

It is to be noticed that, after correction for the isotopic effect, the NRC experimental difference (Cu-M$1-\mathrm{F} 15)_{\mathrm{NRC}}=-165(200) \mu \mathrm{K}$ becomes $(\mathrm{Cu}-\mathrm{M}-1-\mathrm{F} 15)_{\text {thermal }}$ $+147(220) \mu \mathrm{K}$. However, this change does not require a correction in the procedure Section 2.1.1(v) nor an iteration of the calculations, since in (v) one must use the KCRV based on which the values of the $\Delta T_{\text {or }}$ in Table 2 were computed, as taken from [19].

\subsubsection{Comparison K2.1 (VNIIFTRI, NRC)}

In this comparison, the NRC reference cell was still F15. The isotopic composition of the VNIIFTRI sample used in the CCT-K2 is unknown, so no computation is possible to take it into account. Therefore, the measured differences $+0.28 \mathrm{mK}(\# 1)$ and $+0.22 \mathrm{mK}(\# 2)$ remain unchanged.

Should one assume that the sample in question is from the same bottle that was used for the cell participating to the 1978-84 Inter-comparison [34] and the more recent Star Inter-comparison [12], an isotopic correction of $-0.29 \mathrm{mK}$ would apply, leading to a difference of $-0.01 \mathrm{mK}(\# 1)$ and $-0.07 \mathrm{mK}(\# 2)$, respectively.

\subsubsection{Comparison K2.3 (NMI-VSL, NRC)}

In this comparison, the NRC reference cell was changed to the newest $\mathrm{Cu}-\mathrm{M}-1$, whose uncorrected difference from cell F15 has been measured at NRC (though cell F17) to be [ $T$ $(\mathrm{Cu}-\mathrm{M}-1)-T(\mathrm{~F} 15)]_{\mathrm{bc}}=-165(200) \mu \mathrm{K}$. See Table 3 for the values before and after correction of $T_{90}(12 \mathrm{Ne}), T_{90}(\mathrm{~F} 15)$ and $T_{90}(\mathrm{Cu}-\mathrm{M}-1)$

NMI-VSL used INRIM cell $12 \mathrm{Ne}$ (5N gas sample from Messer Griesheim, with assay \#11, [15] assigned isotopic correction $123 \mu \mathrm{K})$. Thus, from Table 3 the values after correction are $[T(12 \mathrm{Ne})-T(\mathrm{Cu}-\mathrm{M}-1)]=-0.00055 \mathrm{~K}, \quad[T$ $(12 \mathrm{Ne})-T(\mathrm{~F} 15)]=-0.00040 \mathrm{~K} \quad$ and $\quad\left[T(12 \mathrm{Ne})-T_{90}\right]=-$ $0.00055 \mathrm{~K}^{6}$

\footnotetext{
$\overline{\overline{6} \text { The above values derive }}$ from considering the NRC F15 as the reference cell for the original CCT K2 [19]. The $\mathrm{KCRV}_{\mathrm{K} 2 . x}$ remains that of the CCT-K2.
}

\subsubsection{Comparison K2.4 (INTiBS, LNE-INM, NRC)}

In this comparison, the NRC reference cell was also the newest $\mathrm{Cu}-\mathrm{M}-1-$ see comparison K2.3.

INTiBS used INRIM cell E3Ne (5N gas sample from Messer Griesheim, with assay \#11, [15] assigned isotopic correction $123 \mu \mathrm{K}$ ). Thus, from Table 3 one gets the value of $T_{90}(\mathrm{E} 3 \mathrm{Ne})$ and the values after correction are $[T(\mathrm{E} 3 \mathrm{Ne})-T(\mathrm{Cu}-\mathrm{M}-1)]=-0.00015 \mathrm{~K},[T(\mathrm{E} 3 \mathrm{Ne})-T(\mathrm{~F} 15)]=$ $0 \mathrm{~K}$ and $\left[T(\mathrm{E} 3 \mathrm{Ne})-T_{\mathrm{KCRV}}\right]=-0.00015 \mathrm{~K}^{7}$

LNE-INM used cell Ne02/1 (5N gas sample from Air Liquide, with assay \#14, [15] assigned isotopic correction $-32 \mu \mathrm{K})$. Thus, from Table 3 one gets the value of $T_{90}(\mathrm{Ne} 02 / 1)$ and the values after correction are $[T(\mathrm{Ne} 02 /$ $1)-T(\mathrm{Cu}-\mathrm{M}-1)]=-0.00042 \mathrm{~K}, \quad[T(\mathrm{Ne} 02 / 1)-T(\mathrm{~F} 15)]=$ $-0.00027 \mathrm{~K}$ and $\left[T(\mathrm{Ne} 02 / 1)-T_{\mathrm{KCRV}}\right]=-0.00042 \mathrm{~K} .^{7}$

\subsubsection{Comparison K2.5 (NMIJ-AIST, INRIM, NRC)}

This comparison is the only one supplied with the results corrected for the isotopic composition of the samples. This requires an inverse computation in order to get the values before correction. For this comparison, the NRC reference cell was also the newest $\mathrm{Cu}-\mathrm{M}-1$-as with comparisons K2.3 and K2.4.

NMIJ-AIST used its cell Ne-5 (5N gas sample from AirWater, with assay \#7, [15] assigned isotopic correction $4 \mu \mathrm{K})$. Thus, from Table 3 one gets the value of $T_{90}(\mathrm{Ne}-5)$ and the values after correction are $[T(\mathrm{Ne}-5)-T(\mathrm{Cu}-\mathrm{M}-$ $1)]=-0.00032 \mathrm{~K}, \quad[T(\mathrm{Ne}-5)-T(\mathrm{~F} 15)]=-0.00018 \mathrm{~K} \quad$ and $\left[T(\mathrm{Ne}-5)-T_{\mathrm{KCRV}}\right]=0.00032 \mathrm{~K}^{7}$

INRIM used cell Ec2Ne (5N gas sample from Messer Griesheim, with assay \#11, [15] assigned isotopic correction $123 \mu \mathrm{K})$. Thus, from Table 3 one gets the value of $T_{90}(\mathrm{Ec} 2 \mathrm{Ne})$ and the values after correction are $[T(\mathrm{Ec} 2 \mathrm{Ne})-$ $T(\mathrm{Cu}-\mathrm{M}-1)]=0.00059 \mathrm{~K},[T(\mathrm{Ec} 2 \mathrm{Ne})-T(\mathrm{~F} 15)]=0.00044 \mathrm{~K}$ and $\left[T(\mathrm{Ec} 2 \mathrm{Ne})-T_{\mathrm{KCRV}}\right]=0.00059 \mathrm{~K}^{7}$

\subsection{Uncertainty of the CCT-K2 comparisons}

The uncertainty issue has been treated separately in Table 4, since its complex analysis requires a full table.

Table 3 shows an important issue: every comparison exercise adds uncertainty to the previous results, in average a $30 \%$ more when comparing $U_{\mathrm{KC}}$ to $U_{\mathrm{TO}}$ lab. In addition, as expected, the increase is larger for the late K2.1-K2.5 $(\approx 30 \%)$ than for the original K2 $(\approx 20 \%)$.

Another very important issue is that, by strongly decreasing the uncertainty on the isotopic composition, one strongly affects the overall laboratory uncertainty budget of the comparison of neon samples: in fact the average contribution of the isotopic effect is of 305(97) $\mu \mathrm{K}$ out of a total of $361(145) \mu \mathrm{K}$, so accounting for more than half.

Since the isotopic uncertainty drops in average from $305(97)$ to $37(33) \mu \mathrm{K}$, the laboratory differences decrease by about $30 \%$ in average after compensating for the isotopic effect, and the comparison uncertainty accordingly: the benefit of the corrections amounts in average to $60(15) \%$, i.e. it cuts the comparison uncertainty by more than half. 


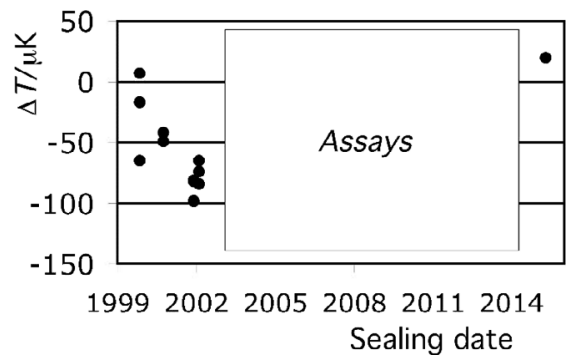

Fig. 3. Differences between samples drawn at INRIM at different times (from left to right) from the same bottle; zero of $\Delta T$ arbitrary, hydrostatic head correction applied. Sealing dates of INRIM cells: from left, cell $12 \mathrm{Ne}-15 \mathrm{Ne}$; cell E2-E4Ne; cell Ec1Ne; cell Ec2Ne; cell Ec29Ne sealed and measured in 2015. Uncertainty of each determination is $\pm \approx 50 \mu \mathrm{K}$.

\section{Discussion and final remarks}

Figure 2 shows a graphical representation of data reported in Table 3: the mean value of the original deviations $\Delta T_{\text {or }}$ is $-147(268) \mu \mathrm{K}^{7}$ for set $\# 1$ and $-166(309) \mu \mathrm{K}$ for set $\# 2$, while those after correction, $\delta T_{\text {iso }}=\left(T_{90 \mathrm{ac}}-\mathrm{KCRV}_{\mathrm{ac}}\right)$, are $-175(306) \mu \mathrm{K}$ for set $\# 1$ and $-187(388) \mu \mathrm{K}$ for set $\# 2$, thus basically the same: this only means that the (obviously unknown) thermal contributions to the deviations are dominant.

However, when subtracting from the original differences the contribution of the isotopic effect, in Figure 4 one gets for $\delta T_{\text {thermal,ac }}-167(233) \mu \mathrm{K}$ for set $\# 1$ and -147 (240) $\mu \mathrm{K}$ for set $\# 2$, where the uncertainty is reduced by $60 \%$ in average, as already observed in Table 4 . In addition, apart for two samples, the deviations after correction are within the interval $(+0.3,-0.2) \mathrm{mK}$, while in Figure 2 they were in the wider interval $(+0.4,-0.8) \mathrm{mK}$.

Therefore, by taking into account the isotopic effect, one can have a substantial improvement in the quality of the comparison results of the CCT-K2.x, though the uncertainty will necessarily increase progressively by adding up new comparisons, as it happened for the supplementary comparisons on the same fixed point see Table 4 and Section 2.2.

In some cases, it is also possible to compare cell differences of INRIM production or of cells of other NMIs directly measured also at INRIM [4] with the values obtained from the K2.x ones.

In Figure 3 the following cells are shown, all sealed with gas taken from the same bottle of gas (Messer Greisheim, analysis \#11 [15]): from the left, 2000: INTiBS (INRIM) cell 15Ne; 2000: VSL (INRIM) cell 12Ne [25] that was made in the same batch (21 Oct 1999) of cell 15Ne; 2001: INRIM cell E3Ne [24], that was made in the same batch (24 Aug 2000) of cell E4Ne; 2001: PTB (INRIM) E1Ne (12 Dec 1999) [12] that was sealed two months before the E2Ne to E4Ne batch; 2002: INRIM Ec1Ne and Ec2Ne (reference cell) [4]; finally, 2015: INRIM Ec29Ne that was sealed from the same bottle of gas after its return back to INRIM after the assays at IRMM, and measured in 2015. All results are compatible with each other except the last one with respect

\footnotetext{
${ }^{7}$ In parentheses the standard deviation.
}

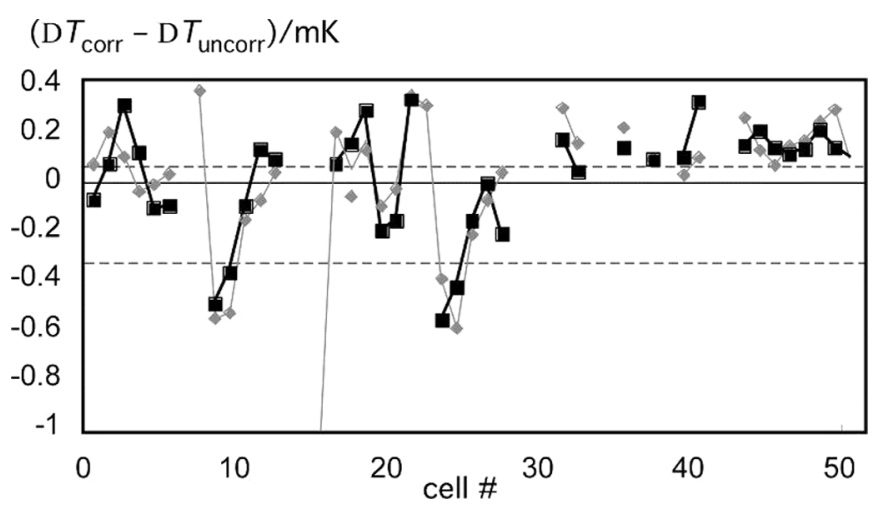

Fig. 4. Graphical representation of differences from the KCRV of K2-xx and Star direct-cell Inter-comparison, uncorrected (gray dots and lines) and corrected (black squares and lines): $\left(T-K C R V_{\mathrm{K} 2 \mathrm{ac}}\right)=\mathrm{D} T_{\text {thermal,ac }}($ Tab. 2$) ; \quad\left(T-\mathrm{KCRV}_{\mathrm{K} 2 \mathrm{bc}}\right)=$ $\Delta T_{\text {original }}$ (Fig. 1). On the left until \#28: K2-xx differences for cells $\# 1$ to $\# 15$ and thermometer sets $\# 1$ and $\# 2 . \Delta T_{\text {original }, \# 1}=-$ $147(268) \mu \mathrm{K}, \Delta T_{\text {original }, \# 2}=-166(309) \mu \mathrm{K} ; \mathrm{D} T_{\text {thermal,ac, } \# 1}=-167$ (233) $\mu \mathrm{K}, \mathrm{D} T_{\text {thermal,ac, } \# 2}=-147(240) \mu \mathrm{K}$. On the right from \#30 to end: Star differences $(56(68) \mu \mathrm{K} ; 74(87) \mu \mathrm{K}$ before isotopic correction), $u=47 \mu \mathrm{K}[12]$. The dotted lines indicate the range of the isotopic effect for the studied samples, as obtained from the MeP [31] in Table 3.

to the 2002 ones. The $+94 \mu \mathrm{K}$ increase of $T_{\mathrm{tp}}$ in 2015 is attributed in [15] to a possible change for unknown reasons of gas isotopic composition within the bottle during the years.

The results of the CCT-K2. $x$ can also be compared in Figure 4 with the results of the largest direct comparison of samples in sealed cells made after the Int84 [34]: the Star Inter-comparison [12], whose data are compared in Table 5 using the data of Table 2.

Figure 4 (right part) makes self-evident the improvement of the Star data (right part) with respect to the K2.x data (left part). Only two samples are outlying: INM Ne02/ 1 and NIST 201. The latter is greyed in Table 5 because traceability back to the right filling gas is unsure. With its exclusion, the mean of the corrected differences is 56 (68) $\mu \mathrm{K}$ (compared with $74(87) \mu \mathrm{K}$ before isotopic correction), thus basically not significant at the $U$ level being the measurement uncertainty $(k=1)$ of $\approx 47 \mu \mathrm{K}$. Except one, all deviations are now within $\pm 50 \mu \mathrm{K}$.

\section{Conclusions}

The inter-comparisons were taken as the main basis of the analysis in this paper because, in order to evaluate the importance of the effect of the isotopic correction, one needs to have a number of "comparable" data.

This does not necessarily mean that the authors suggest to always "correct" previous data, e.g. due to uncorrected significant chemical-impurity effects. However, in this way, one can get the correct understanding of the often-complex procedure to be used for performing the isotopic correction. Originally, that study was undertaken mainly for the latter purpose, then we considered it worth also for comparing different types of inter-comparisons. 
The technical conclusions are as follows.

- The exercise made on the $\mathrm{KC} 2$ has shown that the total uncertainty of the results for neon can be reduced to less than half by making the isotopic correction, because up to $80 \%$ of the original uncertainty budget was due to the contribution of the unknown isotopic compositions (Tab. 3).

- Being the original KC2 uncertainty budget made of two main components - the isotopic one and the instrumental one - the results of the corrected data show instead that the resulting inter-comparison dispersion of the degrees of equivalence (DoE) for the corrected data is basically the same, though the values are obviously different. This means that the instrumental and thermal uncertainty components (including the not-small comparison contribution) is of the same order of magnitude of the isotopic corrections. So one gets basically the same size of the DoEs, but less uncertain.

- The same exercise made on other types of intercomparisons have shown the superiority of the directcell comparison, especially clear for the Star Intercomparison (Tab. 4 and related figure) - see also the OSI.

- Concerning the effect of the chemical impurities (see the OSI), there is not yet, at present, a formal obligation from CCT to make a correction, at least for the cryogenic range: nothing on this matter is included yet in the Technical Annexe to the ITS-90 [31], though CCT documents of the Working Groups already exist. Therefore that Section is placed in the OSI, together with more information on direct-cell inter-comparisons. However, the contribution to the final values and uncertainties of the chemical impurities, though variable depending on their level, in the worst cases can be substantial and even larger than the isotopic effect.

\section{Supplementary Material}

Supplementary Material supplied by the authors. The Supplementary Material is available at https://www. metrology-journal.org/10.1051/ijmqe/2017022/olm.

\section{References}

1. H. Preston-Thomas, Metrologia 27, 3 (1990); Errata 27, 107 (1990)

2. F. Pavese, Metrologia 42, 194 (2005)

3. F. Pavese, Advances in Cryogenic Engineering (Plenum Press, New York, 2006), Vol. 52, p. 451

4. F. Pavese, P.P.M. Steur, N. Bancone, D. Ferri, D. Giraudi, Metrologia 47, 499 (2010)

5. F. Pavese, W.L. Tew, Comité Consultatif de Thermométrie (CCT) Working Document, Doc. CCT/00-9, Bureau International des Poids et Mesures, Sèvres, 2000

6. B. Fellmuth, L. Wolber, Y. Hermier, F. Pavese, P.P.M. Steur, I. Peroni, A. Szmyrka-Grzebyk, L. Lipinski, W.L. Tew, T. Nakano, H. Sakurai, O. Tamura, D. Head, K.D. Hill, A.G. Steele, Metrologia 42, 171 (2005)
7. J.V. Nicholas, D.R. White, T.D. Dransfield, in Proceedings of TEMPMEKO, 1996, Torino, edited by P. Marcarino (Levrotto and Bella, Torino, 1997), p. 9

8. D.R. White, T.D. Dransfield, G.F. Strouse, W.L. Tew, R.L. Rusby, J. Gray, in Proceedings of the Eighth International Temperature Symposium on Temperature, Its Measurement and Control in Science and Industry, 2002, edited by D. Ripple (AIP, New York, 2002), p. 221

9. V. Faghihi, A. Peruzzi, A.T. Aerts-Bijma, H.G. Jansen, J.J. Spriensma, J. van Geel, H.A.J. Meijer, Metrologia 52, 819 (2015)

10. V. Faghihi, M. Kozicki, A.T. Aerts-Bijma, H.G. Jansen, J.J. Spriensma, A. Peruzzi, H.A.J. Meijer, Metrologia 52, 827 (2015)

11. F. Pavese, B. Fellmuth, D. Head, Y. Hermier, K.D. Hill, S. Valkiers, Anal. Chem. 77, 5076 (2005)

12. B. Fellmuth, L. Wolber, D. Head, Y. Hermier, K.D. Hill, T. Nakano, F. Pavese, A. Peruzzi, V. Shkraba, A.G. Steele, P.P. M. Steur, A. Szmyrka-Grzebyk, W.L. Tew, L. Wang, D.R. White, Metrologia 49, 257 (2012)

13. F. Pavese, P.P.M. Steur, Y. Hermier, K.D. Hill, K.J. Seog, L. Lipinski, K. Nagao, T. Nakano, A. Peruzzi, F. Sparasci, A. Szmyrka-Grzebyk, O. Tamura, W.L. Tew, V. Valkiers, J. van Geel, in Proceedings of the Ninth International Temperature Symposium on Temperature, Its Measurement and Control in Science and Industry, 2012, AIP Conf. Proc. (2013), Vol. 1552, p. 192

14. P.P.M. Steur, F. Pavese, B. Fellmuth, Y. Hermier, K.D. Hill, K.J. Seog, L. Lipinski, K. Nagao, T. Nakano, A. Peruzzi, F. Sparasci, A. Szmyrka-Grzebyk, O. Tamura, W.L. Tew, S. Valkiers, J. van Geel, Metrologia 52, 104 (2015)

15. P.P.M. Steur, Y. Inseok, K.J. Seok, T. Nakano, K. Nagao, F. Pavese, in Proceedings of TEMPMEKO 2016, Zakopane, submitted to IUPAC PAC

16. A. El Matarawy, M.G. Ahmed, Int. J. Metrol. Qual. Eng. 5, 401 (2014); A. El Matarawy, M.G. Ahmed, Int. J. Metrol. Qual. Eng. 7, 107 (2016)

17. C. Cappella, F. Sparasci, L. Pitre, B. Buée, A. El Matarawy, Int. J. Metrol. Qual. Eng. 6, 405 (2015)

18. CCT-K1 (NPL Pilot), http://kcdb.bipm.org/appendixB/ KCDB_ApB_info.asp?cmp_idy $=453 \& \mathrm{cmp} \_$cod $=$CCT-K1 \&prov=exalead

19. CCT-K2 (NRC Pilot), http://kcdb.bipm.org/appendixB/ KCDB_ApB_info.asp?cmp_idy $=454 \& \mathrm{cmp} \_$cod $=$CCT-K2 \&prov=exalead

20. CCT-K7 (BIPM Pilot), http://kcdb.bipm.org/appendixB/ KCDB_ApB_info.asp?cmp_idy $=459 \& \mathrm{cmp} \_$cod $=\mathrm{CCT}-\mathrm{K} 7$ \&prov=exalead

21. CCT-K1.1 (NIST (Pilot), NMIJ-AIST), http://kcdb.bipm. org/appendixB $/ \mathrm{KCDB} \_$ApB_info.asp? cmp_idy $=794 \& \mathrm{~cm}$ p_cod=CCT-K1.1\&prov $=$ exalead

22. EÜROMET.T-K1 (INRIM, INTiBS, NPL, PTB (Pilot), VSL), http://kcdb.bipm.org/appendixB/KCDB_Ap B_info.asp?cmp_idy $=1290 \& \mathrm{cmp} \_$cod=EURAMET.TK1&prov=exalead (Final Report). C. Gaiser, B. Fellmuth, P. P.M. Steur, A. Szmyrka-Grzebyk, H. Manuszkiewicz, L. Lipinski, A. Peruzzi, R.L. Rusby, D. Head, Metrologia 54, Technical Suppl. 03002 (2017)

23. CCT-K2.1 (NRC (Pilot), VNIIFTRI), http://kcdb.bipm. org/appendixB/KCDB_ApB_info.asp?cmp_idy $=697 \& \mathrm{~cm}$ p_cod=CCT-K2.1\&prov $=$ exalead

24. CCT-K2.4 (INTiBS, LNE, NRC (Pilot)), http://kcdb.bipm. org/appendixB $/ \mathrm{KCDB} \_$ApB_info.asp? cmp_idy $=745 \& \mathrm{~cm}$ p_cod $=$ CCT-K2.4\&prov $=$ exalead 
25. CCT-K2.3 (NMI-VSL, NRC (Pilot)), http://kcdb.bipm.org/ appendixB/KCDB_ApB_info.asp?cmp_idy $=744 \& \mathrm{~cm}$ p_cod $=$ CCT-K2.3\&prov $=$ exalead

26. CCT-K2.5 (INRIM, NMIJ-AIST, NRC (Pilot)), http:// kcdb.bipm.org/appendixB/KCDB_ApB_info.asp?cmp_i $\mathrm{dy}=771 \& \mathrm{cmp}$ cod=CCT-K2.5\&prov=exalead. K.D. Hill, T. Nakano, P.P.M. Steur, Metrologia 52, Technical Suppl. 03003 (2015)

27. CCT-K2.2 (INRIM, NIM, NRC (Pilot)), not completed yet

28. EUROMET-K7.1 (NMI-VSL (Pilot), several others), http:// kcdb.bipm.org/appendixB/KCDB_ApB_participant.asp? cmp_idy $=789 \& c m p \_c o d=E U R O \bar{M} E T . T-K 7 \& p r o v=$ exa lead

29. http://kcdb.bipm.org/appendixB/KCDB_ApB_info.asp? cmp_idy $=855 \& \mathrm{cmp} \_$cod $=$APMP.T-K7\&prov $=$exalead

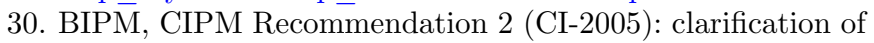
the definition of the Kelvin, unit of thermodynamic temperature, http://www.bipm.org/en/si/si_brochure/ chapter2/2-1/kelvin.html

31. BIPM, Mise en pratique for the definition of the Kelvin and its Technical Annex 2014, http://www.bipm.org/en/si/ si_brochure/chapter2/2-1/kelvin.html

32. W.L. Tew, C.W. Meyer, Doc. CCT/08-09, BIPM, Sèvres, 2009
33. P.P.M. Steur, D. Giraudi, in Proceedings of the Ninth International Temperature Symposium on Temperature, Its Measurement and Control in Science and Industry, 2012, Amer. Inst. Phys. Conf. Proc. (American Institute of Physics, New York, 2013), Vol. 1552, p. 124

34. F. Pavese, J. Ancsin, D.N. Astrov, J. Bonhoure, G. Bonnier, G.T. Furukawa, R.C. Kemp, H. Maas, R.L. Rusby, H. Sakurai, Ling Shankang, Metrologia 20, 127 (1984). Full Report available as: F. Pavese, Final Report, Monograph 84/ 4 of Bureau International des Poids et Mesures, BIPM Sèvres (1984) pp. 1-219 (http://www.bipm.org/en/publications/ monographies-misc.html). In the format of a CCT-KC: F. Pavese, Comptes Rendus Comité Consultatif de Thermométrie, BIPM, Sèvres, Doc. CCT/2000-7, 2000

35. F. Pavese, Int. J. Thermophys. 35, 1077 (2014)

36. M.E. Wieser, T.B. Coplen, Pure Appl. Chem. 83, 359 (2011)

37. F. Pavese, P.P.M. Steur, S. Valkier, T. Nakano, H. Sakurai, O. Tamura, A. Peruzzi, B. Fellmuth, L. Wolber, L. Lipinski, A. Szmyrka-Grzebyk, W.L. Tew, K.D. Hill, A.D. Steele, Y. Hermier, F. Sparasci, Int. J. Thermophys. 31, 1633 (2010)

38. F. Pavese, B. Fellmuth, D. Head, Y. Hermier, A. Peruzzi, A. Szmyrka Grzebyk, L. Zanin, in Proceedings of the Eighth International Temperature Symposium on Temperature, Its Measurement and Control in Science and Industry, 2002, edited by D. Ripple (Amer. Inst. Phys., New York, 2003), p. 161

Cite this article as: Franco Pavese, Anna Szmyrka-Grzebyk, Peter P.M. Steur, The ITS-90 after definition of neon isotopic reference composition: extent of the isotopic effect tested on previous inter-comparison results, Int. J. Metrol. Qual. Eng. 8, 27 $(2017)$ 